IZA DP No. 229

Unions, Increasing Returns and Endogenous Fluctuations

Rui Coimbra

Teresa Lloyd-Braga

Leonor Modesto

December 2000 


\title{
Unions, Increasing Returns and Endogenous Fluctuations
}

\author{
Rui Coimbra \\ FCEE, Universidade Católica Portuguesa \\ Teresa Lloyd-Braga \\ FCEE, Universidade Católica Portuguesa \\ Leonor Modesto \\ FCEE, Universidade Católica Portuguesa and IZA, Bonn
}

Discussion Paper No. 229

December 2000

\author{
IZA \\ P.O. Box 7240 \\ D-53072 Bonn \\ Germany \\ Tel.: +49-228-3894-0 \\ Fax: +49-228-3894-210 \\ Email: iza@iza.org
}

This Discussion Paper is issued within the framework of IZA's research area Mobility and Flexibility of Labor Markets. Any opinions expressed here are those of the author(s) and not those of the institute. Research disseminated by IZA may include views on policy, but the institute itself takes no institutional policy positions.

The Institute for the Study of Labor (IZA) in Bonn is a local and virtual international research center and a place of communication between science, politics and business. IZA is an independent, nonprofit limited liability company (Gesellschaft mit beschränkter Haftung) supported by the Deutsche Post AG. The center is associated with the University of Bonn and offers a stimulating research environment through its research networks, research support, and visitors and doctoral programs. IZA engages in (i) original and internationally competitive research in all fields of labor economics, (ii) development of policy concepts, and (iii) dissemination of research results and concepts to the interested public. The current research program deals with (1) mobility and flexibility of labor markets, (2) internationalization of labor markets and European integration, (3) the welfare state and labor markets, (4) labor markets in transition, (5) the future of work, (6) project evaluation and (7) general labor economics.

IZA Discussion Papers often represent preliminary work and are circulated to encourage discussion. Citation of such a paper should account for its provisional character. 
IZA Discussion Paper No. 229

December 2000

\section{ABSTRACT \\ Unions, Increasing Returns and Endogenous Fluctuations}

We analyse the implications of unions (efficient bargaining) for multiplicity of stationary states and welfare, local indeterminacy, bifurcations and endogenous fluctuations (deterministic and stochastic). We use an overlapping generations model with external increasing returns to scale, where capital is the unique asset. We find that a slight increase in unions power may increase the levels of capital, employment and the welfare of all agents at the steady state. However multiple steady states may exist. Moreover, our results show that increasing returns to scale are a necessary condition for the emergence of deterministic endogenous fluctuations. However, we find that union's bargaining power can dramatically influence the local stability of the system. In fact, while an increase in the bargaining power of unions reduces the scope for local indeterminacy, the emergence of endogenous fluctuations, through Hopf bifurcations may become more likely when unions are present. Therefore, if the relevant trajectory exhibits endogenous fluctuations, steady state welfare is no longer the unique important element from a social point of view. In this case, whether unions are 'good' institutions or not may well depend on the trade off between efficiency and intergenerational equity that society is willing to take.

JEL Classification: E32, J51, D60, D62

Keywords: Unions, increasing returns, endogenous fluctuations

Leonor Modesto

Universidade Católica Portuguesa

FCEE

Palma de Cima

1649-023 Lisboa

Portugal

Tel.: +351-21 7214242

Fax : +351-21 7270252

Email: Irm.fcee.ucp.pt 


\section{Introduction}

In this paper we consider an overlapping generations economy with increasing returns to scale due to positive production externalities. Our aim is to analyse the effects of trade unions on the performance of this economy. We study the role of unions with respect to steady state levels of employment, capital accumulation, capital per worker and welfare. We also study the impact of unions on the emergence of multiple steady states. Moreover we analyse the emergence of local indeterminacy, bifurcations and endogenous fluctuations, i.e. fluctuations driven by self fulfiling volatile expectations (deterministic or stochastic due to extrinsic uncertainty).

We find that, although the steady state utility of all agents may increase when unions are present, unions may also become an additional source of instability, enhancing the emergence of fluctuations. Along trajectories exhibiting endogenous fluctuations some generations are better than in the steady state but others are worst. Hence, the presence of unions may bring benefits for the economy at the steady state, but may also be problematic from an intergenerational equity point of view.

The effects of unions on the accumulation of capital, through their impact on wages and employment, have been recognized for a long time. The conventional view states that as unions increase wages, this will induce from the typical competitive firm a substitution out of labour into capital. However, as an increase in wages produces a negative output effect, both the demand for labour and capital fall, making the net effect on capital ambiguous. Even though, the dominant opinion seems to be that the net effect is negative, so that unions harm capital accumulation and therefore growth and welfare. ${ }^{1}$ More recently Devereux and Lockwood (1991), using an OLG model, have shown that in a general equilibrium setting the negative net result may be reversed. In a partial equilibrium framework interest rates are exogenously fixed. However, in a general equilibrium framework the interest rate change when unions are present. This means that the final outcome becomes ambiguous, so that an increase in union power may well increase

\footnotetext{
${ }^{1}$ Grout (1984) shares the same view, stressing however a different mechanism. The basic idea is that when unions and firms bargain over both the wage and employment (the efficient bargain case), in the absence of binding wage contracts as a union cannot commit in advance to a given wage path, wages will be determined taking the capital stock as given. A higher capital stock induces therefore higher wage demands from the union, wich in turn decrease profits and therefore investment.
} 
capital accumulation. Indeed, in standard OLG models, capital accumulation in the economy usually comes out from wages. As unions typically are able to increase wages it is not strange that capital increases may be obtained when unions have a higher bargaining power. Devereux and Lockwood, using a Cobb-Douglas production function without externalities and considering employment constant, showed that unions not only have a positive effect on capital acumulation but also on the utility level of workers at the steady state.

In this paper we extend Devereux and Lockwood's paper in two different directions: we develop their model and we extend the focus of analysis. On one hand, in our model, labour supply decisions are endogenous. In this setting, the impact of unions on steady state welfare, also depends on their effect on the employment level. We also consider a more general production function, where the elasticity of substitution between capital and labour need not be constant or identical to one. In this case whether unions are able or not to increase the steady state level of capital per worker also depends on the value of this elasticity. ${ }^{2}$ Moreover, we consider positive externalities in production. As it is well known, in this case it is less likely that a perfectly competitive economy will be dynamically inefficient. Therefore, an increase in capital per worker may have an additional positive impact on welfare. Our results show that a slight increase in the bargaining power of unions may increase employment, capital and capital per worker, as well as welfare at the steady state for reasonable values of the parameters of the model. As we shall also see our economy may have multiple steady states.

On the other hand, the focus of our analysis is novell as it has also to do with the implications of unions for the local dynamics of the model and for the emergence of endogenous fluctuations (deterministic and stochastic). Indeed, the present study develops the existing studies of endogenous fluctuations in economies with capital accumulation to the case where the labour market is not perfectly competitive. Within an OLG framework the pioneer work on endogenous fluctuations in economies with capital accumulation is Reichlin (1986). ${ }^{3}$ He showed that endogenous fluctuations may emerge

\footnotetext{
${ }^{2}$ However, as we shall see, for reasonable values of the elasticity of substitution between capital and labour in production an increase in the bargaining power of unions also increases capital per worker at a steady state. See Hamermesh (1993) were empirical values of this elasticity are given and typically range between 0.4 and 2 .

${ }^{3}$ The standard OLG model, as in Reichlin, generates similar dynamics to the Woodford model (1986), when a Leontief technology is considered. de Vilder (1996) uses both models
} 
due to the occurrence of Hopf bifurcations, when constant returns to scale are considered, but only for a sufficiently low elasticity of substitution between capital and labour. More recently, Lloyd-Braga (1995) and Cazzavillan and Pintus (1998) showed the compatibility between endogenous fluctuations and higher values of the elasticity of factor substitution when the model is amended to incorporate increasing returns. ${ }^{4}$ In Coimbra (1999), the indivisible labour hypothesis (Hansen (1985)) together with increasing returns was introduced. ${ }^{5}$ He showed that the emergence of endogenous cycles is quite plausible, occurring with both an elasticity of inputs substitution and an amount of increasing returns in consonance with empirical evidence. ${ }^{6}$

In this paper we pursue this latter analysis, i.e., we consider the existence of increasing returns due to positive externalities in production and indivisible labour. We assume that agents are identical and indifferent between working a fixed number of hours or not working if wages are identical to the reservation wage. Moreover, we consider the existence of an (efficient) bargaining, between unions and firms, over wages and employment. ${ }^{7}$ The case of a perfectly competitive economy is recovered as the case where unions bairgaining power is null. Under this set up, at equilibrium, full employment may not be obtained. Indeed, even under perfect competition in the labour market, as in d'Aspremont et al. $(1995)^{8}$, underemployment is likely to emerge and we restrict our analysis to this type of equilibria. We obtain the perfect foresight dynamic system and analyse the local stability proper-

to present a local and global dynamic analisys.

${ }^{4}$ Cazzavillan et al (1998) got similar results in a Woodford's (1986) type of model. Increasing returns may be internal to the firm or due to positive externalities in production. In the first case imperfect competition should be considered. Note, however, that under imperfect competition markup variability may also be important for the emergence of endogenous fluctuctions. Gali (1994) using a model where agents have an infinite horizon has shown that local indeterminacy may appear due to markup variability.

${ }^{5}$ In Coimbra (1999) the efficiency wages structure is considered and the level of effort is endogenously obtained. See also Pintus (1997) where efficiency wages are also considered.

${ }^{6}$ Although there is some empirical evidence for the existence of increasing returns, the degree of returns to scale seems to be not much higher than 1 . See for instance Caballero and Lyons (1990).

${ }^{7}$ See also Jacobsen (2000) where the influence of imperfect competition (where firms set prices and unions set wages) on the emergence of cycles is analysed, using a model without capital.

${ }^{8}$ d'Aspremont et al (1995) also studied the effects of increasing returns on endogenous fluctuations in a model where there is underemployment, but they did not consider capital accumulation. 
ties of the steady state, as well as the occurence of local bifurcations. We use a geometrical method, as in Grandmont et al. (1998), which provides a simple but comprehensive way of analysing the emergence of endogenous fluctuations around a steady state. We find that union's bargaining power dramatically influences the local dynamics of the system. As we shall see an increase in the bargaining power of unions reduces the scope for local indeterminacy. Also, the emergence of endogenous fluctuations, through Hopf bifurcations, become more likely when unions are present.

The rest of the paper is organized as follows. In section 2 we describe the model and obtain the dynamic equations. In section 3 we do the steady state analysis and discuss the steady state effects of union power. In section 4 we present the local dynamics and bifurcation analysis. Finally in section 5 we present some concluding remarks.

\section{The Model}

We consider an overlapping generations model of two-period lived agents. In each period, $t=1,2 \ldots \infty$, a continuum of identical individuals (households) of mass $N$ is born. Therefore in each period $t$ there are two generations alive, the young born at $t$ and the old born at $t-1$. Individuals may consume in youth and in old age but can only work when young. Young individuals can either work a fixed amount of hours for a firm, receiving a wage $W_{t}$, or not work at all. ${ }^{9}$ They are only willing to work if wages are set above a certain value, the reservation wage $\bar{W}_{t} \cdot{ }^{10}$ In each period there is a single output, exchanged under perfect competition, which is either consumed or added to the capital stock. Output is the numeraire. In every period $t$ there are $m$ identical firms ${ }^{11}$ each producing a quantity of output using labour, $L_{t}$, and capital, $K_{t}$. Capital services are rented each period in a perfectly competitive market. Wages and employment are determined through a bargaining process (eficient bargaining) between unions and firms.

\footnotetext{
${ }^{9}$ This means that, as in Coimbra (1999) we consider the indivisible labour hypothesis.

${ }^{10}$ When $W_{t}=\bar{W}_{t}$ young individuals are indifferent between working or not. Note that as households are identical they all face the same $\bar{W}_{t}$.

${ }^{11}$ We assume that in each period firms's ownership is exogenously distributed among the old generation. Therefore, we do not consider the existence of a stock market, so that, as in standard OLG models with capital, capital is the unique asset.
} 


\subsection{Unions and firms}

\subsubsection{Unions}

Unions are firm-specific, i.e. we have one union per firm. Unions represent all youngsters. We assume that at the begining of each period $t$ the young are matched exogenously and uniformly with unions ${ }^{12}$ so that each of the $m$ identical unions represents $n=N / m$ young individuals. We assume that unions are utilitarian. See Oswald (1982). This means that each union treats all members symmetrically and maximises the sum of all of its members utilities, whether employed or not. In our case, as it will become apparent later on, this is equivalent to consider the following objective for the representative union:

$$
\Omega_{t} \equiv h\left(W_{t}-\bar{W}_{t}\right) L_{t}
$$

where $h>0$ is a constant and $L_{t}$ is employment at the firm.

\subsubsection{Firms}

We assume that the private production function of a representative firm exhibits constant returns to scale. However, increasing returns at the social level may exist, due to positive external effects in the production process: $\Psi\left(\bar{K}_{t}, \bar{L}_{t}\right)$, where $\Psi$ is an increasing function of the average capital stock $\bar{K}$, and employment in the economy $\bar{L} \cdot{ }^{13}$ We use externalities to combine a social technology that displays increasing returns with a competitive behaviour in the output market. ${ }^{14}$ Each small individual producer $(m$ big) takes $\bar{K}$ and $\bar{L}$ as given when solving his optimising problem.

Accordingly, we consider the following production function:

$$
\Psi\left(\bar{K}_{t}, \bar{L}_{t}\right) A F\left(K_{t}, L_{t}\right)=\Psi\left(\bar{K}_{t}, \bar{L}_{t}\right) A L_{t} f\left(X_{t}\right)
$$

where $X=K / L$ is the capital labour ratio and $A>0$ is a scaling factor. The second expression follows from the constant returns to scale assumption. We further assume that:

\footnotetext{
${ }^{12}$ Workers cannot move between firms or unions.

${ }^{13}$ Positive externalities are usually justified by learning by doing, learning spillovers or public knowledge arguments.

${ }^{14}$ This device has been widely used in macro dynamic models. See, for instance, Farmer and Guo (1994), Benhabib and Farmer (1994) and Cazzavillan et al. (1998).
} 
Assumption $1 f(X)$ is a real, continuous function for $X \geq 0$, positively valued and differentiable as many times as needed for $X>0$, with $f^{\prime}(X)>0$, $f^{\prime \prime}(X)<0$ and $f(X)-f^{\prime}(X) X>0 . \Psi$ is a real, positively valued function, continuous on $\Re_{+}^{2}, C^{r}$ on $\Re_{++}^{2}$, for $r$ large enough. We also assume that $\varepsilon_{\Psi, \bar{K}}=\Psi_{\bar{k}}^{\prime} \overline{\frac{k}{\Psi}} \geq 0$ and $\varepsilon_{\Psi, \bar{L}}=\Psi_{\bar{l}}^{\prime} \overline{\frac{l}{\Psi}} \geq 0$. Moreover $\Psi$ is homogeneous of degree $v$, where $v=\varepsilon_{\Psi, \bar{K}}+\varepsilon_{\Psi, \bar{L}}$ measures the degree of increasing returns to scale, which is zero if there are no externalities ( $\Psi$ constant).

In each period producers maximize profits: $\pi_{t} \equiv \Psi\left(\bar{K}_{t}, \bar{L}_{t}\right) A L_{t} f\left(X_{t}\right)-$ $W_{t} L_{t}-r_{t} K$, where $r_{t}$ is the rental price of capital. Producers, when maximising profits, solve a two-stage problem. First, at the begining of period $t$ producers, given $r_{t}$, rent capital on the economy-wide capital market. After this wages and employment are determined through a bargain between unions and firms on the distribution of the surplus over and above capital rental costs. ${ }^{15}$ Finally production takes place. The income generated in production, after the payment of the rental cost of capital, is then distributed among workers and the owners of the firms.

A relevant issue in the modelisation of this problem concerns the degree of commitment allowed for the wage-employment contract. We assume that workers cannot sign binding wage contracts, so that the wage and employment are determined after the capital stock decision has been made. Therefore to ensure time consistency of the equilibrium we solve the problem backwards, starting with the wage-employment bargain.

\subsubsection{Wage, employment and capital decisions}

We model the bargaining process using the generalised Nash bargaining solution. ${ }^{16}$ This means that first we have to specify the fallback payoffs of each party, in the event that no agreement is reached. For the union the fallback utility is zero, i.e., as we shall see, the level of utility of an unemployed

\footnotetext{
${ }^{15}$ Note that, by considering a bargain over wages and employment we are assuming the efficient bargaining structure rather than the right-to-manage one. This choice is mainly due to analytical tractability. Indeed, if we had adopted the right-to-manage bargaining framework, the analysis of local dynamic properties in section 4 would involve third order derivatives of the production function. However the right-to-manage assumption is very appealing to study other phenomena. See, for instance, Benassy (1997) where unemployment hysteresis may be linked to this type of bargain.

${ }^{16}$ Note that this solution can been seen as a limit solution of a non-cooperative bargaining game. See Sutton (1986).
} 
worked. For the firm, as we have considered non-binding wage contracts, the fall back profit is minus the rental cost of capital $\left(-r_{t} K_{t}\right) \cdot{ }^{17}$ Hence, the wage and employment at the typical firm solve the following problem:

$$
\underset{\left(W_{t}, L_{t}\right) \in \Re_{++}^{2}}{\operatorname{Max}} \pi_{t}^{*^{\alpha}} \Omega_{t}^{(1-\alpha)}
$$

where $0<\alpha \leq 1$ measures the firm's bargaining power and where:

$$
\pi_{t}^{*} \equiv \pi_{t}-\left(-r_{t} K_{t}\right)=\Psi\left(\bar{K}_{t}, \bar{L}_{t}\right) A L_{t} f\left(X_{t}\right)-W_{t} L_{t} .
$$

From the first order conditions of problem (3) we obtain:

$$
\begin{gathered}
\bar{W}_{t}=\Psi\left(\bar{K}_{t}, \bar{L}_{t}\right) A\left[f\left(X_{t}\right)-f^{\prime}\left(X_{t}\right) X_{t}\right] \\
W_{t}=\Psi\left(\bar{K}_{t}, \bar{L}_{t}\right) A\left[f\left(X_{t}\right)-\alpha f^{\prime}\left(X_{t}\right) X_{t}\right] .
\end{gathered}
$$

We assume that $L_{t}<n=N / m, \forall_{t}$. This means that there is always some degree of underemployment in our economy.

The firm then chooses $K_{t}>0$ to maximize profits that, using (5), can be written as:

$$
\pi_{t}=\alpha \Psi\left(\bar{K}_{t}, \bar{L}_{t}\right) A f^{\prime}\left(X_{t}\right) K_{t}-r_{t} K_{t}
$$

where $X_{t}$ satisfies (4). This yields the first order condition: ${ }^{18}$

$$
\alpha \Psi\left(\bar{K}_{t}, \bar{L}_{t}\right) A f^{\prime}\left(X_{t}\right)=r_{t} .
$$

Substituting now (7) in (6) we can see that profits are zero, i.e. there are no pure profits in equilibrium. ${ }^{19}$ Therefore, there are no dividends to be paid.

\footnotetext{
${ }^{17}$ With binding contracts the fall back profit would be zero as $W$ and $L$ could have been determined before installing the capital stock. Indeed, as the reader can check, if workers could sign binding contracts the solution, in our case, would be equivalent to the competitive outcome. This is due to the indivisible labour assumption and to the fact that the reservation wage is endogenous in our model.

${ }^{18}$ Note that, given (4), the derivative of $\alpha \Psi\left(\bar{K}_{t}, \bar{L}_{t}\right) A f^{\prime}\left(X_{t}\right)$ with respect to $K_{t}$ is zero.

${ }^{19}$ The assumption of constant returns to scale is crucial for this result. Indeed, with decreasing returns to scale profits would be positive, as in Devereux and Lockwood (1991).
} 
Note that when the firm has all the power in the bargaining process ( $\alpha=1$ ) we obtain the competitive outcome: i.e., the rental cost of capital is identical to the marginal productivity of capital (see (7)) and the wage equals both the marginal productivity of labour and the reservation wage (see (4) and (5)).

$>$ From (4) we see that employment is determined by the equality between the marginal productivity of labour $(M P L)$ and the reservation wage, for all $\alpha$. This means that the contract curve is vertical, ${ }^{20}$ so that in a partial equilibrium framework, union power would have no effect on the level of employment. See figure 1. However, as we shall see in section 3.3, in our model union power influences employment through general equilibrium effects. Moreover from (4) and (5) we have that unions are able to set wages above the reservation wage. This mark-up depends positively on unions bargaining power and on the ratio between the marginal contributions of capital and labour for output.

(insert Figure 1 here)

$L^{s}$ represents the labour supply curve and $W_{(\alpha)}$ represents the contract curve. Note that for $\alpha<1$ unemployment is involuntary at the individual level, since in this case all individuals are willing to work at the existing wage. However, underemployment is also present when the labour market is perfectly competitive. Whether in this case unemployment is voluntary or involuntary is more a question of semantic. Indeed, as we shall see in section 3 below, even in this case an increase in employment may be desirable from a social welfare point of view.

Finally, for future reference, note that, using (5) and (2), we obtain the following expression for the labour share of output:

$$
s_{L}=\frac{\left[f(X)-\alpha f^{\prime}(X) X\right]}{f(X)}
$$

where $1>s_{L(X)}>1-\alpha$, from Assumption 1.

\subsection{Households}

We assume that preferences of a representative household born at $t \geq 1$ are additively separable between consumption and labour supplied when young.

\footnotetext{
${ }^{20}$ Note that this result follows from the linearity of $\Omega$ in $W$.
} 
We further assume Cobb-Douglas preferences over consumption while young and old, respectively $C_{1 t}$ and $C_{2 t+1}$. Each individual either decides to work a fixed amount of hours when young $\left(d_{t}=1\right)$, receiving a wage $W_{t}$, or not work at all $\left(d_{t}=0\right)$. The wage income received by a young worker in period $t$ is spent in current consumption or saved through the purchase of productive capital $K_{t+1}^{h}$, available for production at the outset of period $t+1$. We assume that capital fully depreciates after a period of use in production. When old, individuals rent to firms the capital goods, purchased while young, at the expected rate $r_{t+1}$. The problem solved by a representative individual born at $t \geq 1$ is then the following: ${ }^{21}$

$$
\begin{aligned}
\max \quad C_{1 t}^{\beta} C_{2 t+1}^{(1-\beta)}-a d_{t} \\
\text { s.t. } \quad \begin{aligned}
C_{1 t}+K_{t+1}^{h} & =W_{t} d_{t} \\
C_{2 t+1} & =r_{t+1} K_{t+1}^{h}
\end{aligned}
\end{aligned}
$$

where $a>0$ is the desutility of work and $0 \leq \beta<1$.

Then, for an employed young individual $\left(d_{t}=1\right)$ we have that:

$$
\begin{aligned}
C_{1 t} & =\beta W_{t} \\
C_{2 t+1} & =(1-\beta) W_{t} r_{t+1}
\end{aligned}
$$

and:

$$
K_{t+1}^{h}=(1-\beta) W_{t} .
$$

Substituting (12) in (9) we can write the indirect utility function of each employed individual born at $t$ as:

$$
V_{t}=V\left(W_{t}, r_{t+1}\right)=\beta^{\beta}(1-\beta)^{(1-\beta)} r_{t+1}^{(1-\beta)} W_{t}-a .
$$

If unemployed the utility of an individual born at $t$ is zero, since $d_{t}=$ $C_{1 t}=C_{2 t+1}=0$.

An young individual will only be willing to work if $V_{t}>0$. This means that an individual will decide to work only when $W_{t}>\bar{W}_{t}$, where $\bar{W}_{t}$ is the reservation wage given by:

$$
\bar{W}_{t}=a\left[\beta^{\beta}(1-\beta)^{(1-\beta)}\right]^{-1} r_{t+1}^{(\beta-1)}=\delta_{(a, \beta)} r_{t+1}^{(\beta-1)} .
$$

\footnotetext{
${ }^{21}$ We assume that the generation born old at the begining of this economy $(t=1)$ owns all the existing productive capital and spends all the rentals in consumption.
} 
Using the previous expressions, it becomes now clear that an utilitarian union, that takes into account the utilities of all its members, whether employed or not, maximises the following function:

$$
\Omega_{t}=\beta^{\beta}(1-\beta)^{(1-\beta)} r_{t+1}^{(1-\beta)}\left(W_{t}-\bar{W}_{t}\right) L_{t}=h\left(W_{t}-\bar{W}_{t}\right) L_{t}
$$

since the union treats $r_{t+1}$ as given. ${ }^{22}$

\subsection{Equilibrium}

Equilibrium in the labour and capital markets requires that $m K_{t+1}=K_{t+1}^{h} m L_{t}$, i.e. in any period the capital stock in the economy is predetermined by the savings of the previous young generation. Moreover, since all firms are identical, in equilibrium $K_{t}=\bar{K}_{t}$ and $L_{t}=\bar{L}_{t}$. Therefore, using (5) and (13), in equilibrium we have:

$$
K_{t+1}=(1-\beta) L_{t} \Psi\left(K_{t}, L_{t}\right) A\left[f\left(X_{t}\right)-\alpha f^{\prime}\left(X_{t}\right) X_{t}\right]
$$

Also using (4), (7) and (15) we obtain:

$\Psi\left(K_{t+1}, L_{t+1}\right) A f^{\prime}\left(X_{t+1}\right)=\left[\frac{\delta_{(a, \beta)}^{\frac{-1}{(\beta-1)}}}{\alpha}\right]\left\{\Psi\left(K_{t}, L_{t}\right) A\left[f\left(X_{t}\right)-f^{\prime}\left(X_{t}\right) X_{t}\right]\right\}^{\frac{1}{\beta-1}}$

Equations (16) and (17) govern the dynamics of the model. ${ }^{23}$ These equations implicitly define a two dimensional dynamic system with one predetermined variable, $K$.

Definition 1 An intertemporal equilibrium with perfect foresight is a sequence $\left(K_{t}, L_{t}\right) \in \Re_{++}^{2}, t=1,2, \ldots \infty$, such that (16) and (17), where $X=K / L$, are satisfied.

\footnotetext{
${ }^{22}$ The function $\Omega_{t}$, being the sum of all its members utilities will always have this functional form as long as consumption is a linear function of wages. This will happen if preferences over consumption while young and old are represented by a function that is homogeneous of degree one. We chose a Cobb-Douglas specification in order to simplify the analysis.

${ }^{23}$ Note that the output market also clears by Walras law.
} 


\section{$3 \quad$ Steady State Analysis}

In this section we study the existence, uniqueness or multiplicity of the stationary states for our dynamic system. Our analysis will closely follow Cazzavillan et al. (1998) and Aloi et al. (2000).

\subsection{Existence}

Existence is easily established by scaling the two parameters $A$ and $a$ to normalise the steady state values of capital and labour.

A steady state solution $(K, L)$ for all $t$ is a solution of (16)-(17), with $X=K / L$, such that:

$$
\begin{gathered}
K=(1-\beta) L \Psi(K, L) A\left[f(X)-\alpha f^{\prime}(X) X\right] \\
\Psi(K, L) A f^{\prime}(X)=\left[\frac{\delta_{(a, \beta)}^{-\frac{1}{(\beta-1)}}}{\alpha}\right]\left\{\Psi(K, L) A\left[f(X)-f^{\prime}(X) X\right]\right\}^{\frac{1}{\beta-1}}
\end{gathered}
$$

where $(\operatorname{see}(15)) \delta_{(a, \beta)}=a\left[\beta^{\beta}(1-\beta)^{(1-\beta)}\right]^{-1}$.

In what follows we ensure the existence of a steady state, namely with $K=1, L=1$ by choosing appropriate values of the scaling parameters $A>0$ and $a>0$, so that:

$$
\begin{gathered}
1=(1-\beta) \Psi(1,1) A\left[f(1)-\alpha f^{\prime}(1)\right] \\
\Psi(1,1) A f^{\prime}(1)=\left[\frac{\delta_{(a, \beta)}^{-\frac{1}{(\beta-1)}}}{\alpha}\right]\left\{\Psi(1,1) A\left[f(1)-f^{\prime}(1)\right]\right\}^{\frac{1}{\beta-1}}
\end{gathered}
$$

Given Assumption 1 there is a unique solution $A>0$ to (20). Since $\alpha>0$ and $\delta_{(a, \beta)}$ is an increasing function of $a \in R_{++}$, taking values in $(0,+\infty)$ there is also a unique solution $a>0$ to (21), given $A$. Therefore:

\section{Proposition 1 Existence of the steady state}

Under Assumption 1, let $A>0$ and $a>0$ be the unique solutions of (20)-(21) for given values of $\alpha$ and $\beta$; then $(K, L)=(1,1)$ is a stationary solution of the dynamic system (16)-(17). 


\subsection{Uniqueness versus multiplicity}

In view of (18)-(19) finding a stationary solution for the dynamics of the system requires finding a value for $X$ that satisfies:

$$
G(X)=\frac{\alpha f^{\prime}(X)}{\delta^{-\frac{1}{(\beta-1)}}}\left\{\frac{X^{(2-\beta)}\left[f(X)-f^{\prime}(X) X\right]}{(1-\beta)^{(2-\beta)}\left[f(X)-\alpha f^{\prime}(X) X\right]^{(2-\beta)}}\right\}^{\frac{1}{1-\beta}}=1
$$

where $G(X)$ is a continuous positive function for $X>0$. Hence, studying the existence of multiple steady states involves studying the number of solutions in $X$ for $(22) .{ }^{24}$ In particular if $G(X)$ is monotonic (i.e. if either $G^{\prime}(X)>0$ for all $X$ or $G^{\prime}(X)<0$ for all $\left.X\right)$ there exists at most one steady-state, i. e. the one defined in Proposition 1. Also if $G^{\prime}(X)$ changes its sign only once, then, at most, two steady state solutions generically exist. Finally, if $G(X)$ is constant then, by Proposition $1, G(X)=G(1)=1$ for all values of $X$ and there is a continuum of steady states.

To check whether $G(X)$ is monotonic or not, we now analyse the sign of $G^{\prime}(X)$. Differentiating $G(X)$ we obtain:

$\frac{G^{\prime}(X) X}{G(X)}=H(X)=\frac{\left(1-s_{L(X)}\right) s_{L(X)}+\left(\alpha-1+s_{L(X)}\right)\left[(2-\beta)\left(\sigma_{(X)}-1\right)+s_{L(X)}\right]}{(1-\beta) \alpha \sigma_{(X)} s_{L(X)}}$

where $s_{L(X)}$ is the labour share at the steady state, given by $(8)$, and $\sigma_{(X)}$ is the elasticity of substitution between capital and labour in production at the steady state, that is given by:

$$
\frac{1}{\sigma}=-\frac{f(X) f^{\prime \prime}(X) X}{f^{\prime}(X)\left[f(X)-f^{\prime}(X) X\right]}
$$

Note that, by Assumption $1, \sigma_{(X)} \in(0,+\infty)$. Since $X>0$ and $G(X)>0$, studying the sign of $G^{\prime}(X)$ is equivalent to studying the sign of the function $H(X)$. The following proposition presents the main results.

\section{Proposition 2 Uniqueness of the steady state}

\footnotetext{
${ }^{24}$ Indeed by Assumption 1 and using (18) and (19) we know that there is a unique steady state value of $(K, L)$ corresponding to a given $X$ when $v>0$.
} 
Under the assumptions of Proposition 1, there is a unique steady state, $(K, L)=(1,1)$, if one of the following conditions is satisfied:

(i) $\sigma_{(X)}>\sigma_{1}=1-\frac{\alpha s_{L(X)}}{(2-\beta)\left(\alpha-1+s_{L(X)}\right)}$, i.e. $H(X)>0$ for all $X>0$.

(ii) $0<\sigma_{(X)}<\sigma_{1}=1-\frac{\alpha s_{L(X)}}{(2-\beta)\left(\alpha-1+s_{L(X)}\right)}$, i.e. $H(X)<0$ for all $X>0$.

The proposition above shows that when $\sigma$ is constant (the CES case) the cases where $\sigma \geq 1$ fall into configuration (i) and, therefore, the steady state is unique. ${ }^{25}$ Moreover, if $\alpha=1$ (the competitive case) unicity of the steady state is also obtained in the CES case, since either (i) or (ii) are generically satisfied. These results mean that for a constant $\sigma<1$, the steady state is unique if $\alpha=1$, whereas multiplicity may only arise in the presence of unions i.e. when $\alpha<1$.

We adress now the issue of multiplicity versus unicity by analysing the circumstances under which the conditions stated in Proposition 2 are violated. We focus our attention in the cases where $H(X)$ changes sign at most only once. In this case $G(X)$ is either single-caved or single-peaked, so that there are at most two steady states.

\section{Proposition 3 Multiplicity of steady states}

There are, at most, two steady states if either:

(i) $\sigma_{(X)}(2-\beta)\left(\alpha-1+s_{L(X)}\right)-s_{L(X)}[2-(\alpha+\beta)]$ is increasing in $X$ or;

(ii) $\sigma_{(X)}(2-\beta)\left(\alpha-1+s_{L(X)}\right)-s_{L(X)}[2-(\alpha+\beta)]$ is decreasing in $X$.

Under these conditions $H(X)$ changes sign at most once. Under condition (i) $H(X)$ is an increasing function. If $H(0)<0$ and $H(+\infty)>0$, then $H(X)$ crosses the value zero exactly once (from below), and the $G(X)$ function is single-caved. Under case (ii) $H(X)$ is an decreasing function. Hence if $H(0)>0$ and $H(+\infty)<0$, then $H(X)$ crosses the value zero exactly once (from above), and the $G(X)$ function is single-peaked.

Therefore, if the assumptions of Proposition 1 are satisfied and $H(X)$ does not vanish at $X=1$, there are exactly two steady states whenever

\footnotetext{
${ }^{25}$ Note that at the steady state $W L(1-\beta)=K$ since capital is accumulated trough savings of the young employed workers. Hence, at the steady state $W / X=(1-\beta)$. Abstracting from externalities, that do not influence our results on the unicity or multiplicity of steady states, we know that $W$ is a function of $X$ (see (5)). It is easy to check that $W / X$ is a decreasing function of $X$ for all $X>0$ if $\sigma \geq 1$. Therefore, in this case, $W / X$ can not cross more than once the value $(1-\beta)$.
} 
(i) or (ii) of Proposition 3 holds, provided that the appropriate boundary conditions are satisfied (namely that $G(X)-1$ has the same sign for $X$ close to zero and $X$ close to $+\infty)$.

In the nongeneric case where $H(1)=0$ there is exactly one steady state. ${ }^{26}$ Later on in the paper, when local dynamics and bifurcations around the steady state are studied, it can be checked that the case just described, i. e. $H(1)=0$, corresponds to the appearance of a transcritical bifurcation.

\subsection{Steady state effects of union power}

In this section, assuming that a steady state exists (Proposition 1), we analyse the effects of union power, $(1-\alpha)$, on steady state welfare. In order to do this it is convenient to be more specific about the externality function considered. Following Cazzavillan and Pintus (1998) we will assume, from now on, that the external effects due to the average labour stock are equal to zero at the steady state. It implies that $\varepsilon_{\Psi, L}=0$ and $\varepsilon_{\Psi, K}=\nu>0$ (see Assumption $1)^{27}$.

We are mainly interested in understanding if an increase in unions's power has a clear positive effect on economic performance at a steady state. This will be the case if unions are able to increase steady state employment and the representative worker's utility. In this case, if consumption of those already born old also increases, steady state social welfare ${ }^{28}$ would also be higher.

Departing from a perfectly competitive labour market situation $(\alpha=1)$, a slight increase in union's power will have a positive effect on the steady state level $X$ of capital per worker, for reasonable values of the elasticity

\footnotetext{
${ }^{26}$ See Cazzavillan et al. (1998) where it is explained why, under these conditions, the unicity of the steady state does not persist.

${ }^{27}$ This assumption is compatible with the standard learning-by-doing argument (see Arrow (1962), Romer (1986)) where the capital stock only is assumed to originate social increasing returns.

${ }^{28}$ Here, as in Azariadis (1993), we might want to consider a social welfare function of the type $S W F=b_{0} C_{2}+b_{1}\left[U\left(C_{1}, C_{2}\right)-a\right] L+b_{2}(n-L) U_{2}$, where $b_{0}, b_{1}, b_{2}$ are non negative weights and $U_{2}$ is the utility level of those unemployed (zero at the market equilibrium). This means that social welfare is a weighted average of the utilities of all types of households that may exist in a period $t$ where a steady state solution is observed. Remark that the objective function of a representative union is a special case of the SWF presented above, with $b_{0}=0$ and $b_{1}=b_{2}$. However, unions being miopic will never act as a social planner with identical weigths. Indeed unions treat $r$ as given and do not internalise production externalities.
} 
of capital labour substitution (namely for $\left.\sigma>\sigma_{1(\alpha=1)}=(1-\beta) /(2-\beta)\right){ }^{29}$ So we will concentrate in the $\sigma>\sigma_{1}$ case and ask, whether in this case, employment and the utility of workers also increase. Note that if both $X$ and $L$ increase, steady state capital stock also increases.

The fact that unions may simultaneously increase the steady state levels of capital per worker and social welfare may be at first sight puzzling, at least if the competitive market equilibrium is dynamic inefficient. ${ }^{30}$ In this case, on the contrary, a higher level of steady state consumption (welfare) could only be obtained if $X$ decreased. In other words, $X$ was too high at the competitive market equilibrium, and over-accumulation of capital or underemployment of labour force were just two sides of the same coin. ${ }^{31}$ However, externalities may revert this effect. Indeed if, as in our case, positive capital externalities are neutral, affecting the private productivity of labour and capital at the same rate, the accumulation of capital may be beneficial for employment, since, in this case, the marginal productivity of labour increases. Moreover, when positive capital externalities are present, the level of capital at the competitive market equilibrium may be below its efficient level. Hence, in the presence of externalities it is not strange that increases in $X$ may be socially desirable. When and how unions are able to increase steady state employment, capital per worker and the representative worker's welfare is another question that we discuss below.

A change in $\alpha$ influences the stationary solutions $(K, L)$, given by (18)(19), and therefore steady state agents' utility. Consider fixed values for the parameters $a, A$ and $\beta$. Assume that $\left(K^{*}, L^{*}\right)$ is a steady state solution associated with a given $\alpha^{*}$ satisfying (18) and (19). Then, as seen before, the steady state $\left(K^{*}, L^{*}\right)$ is generically locally unique. Moreover, given Assumption $1, K^{*}(\alpha)$ and $L^{*}(\alpha)$ are $C^{r}$ functions for $\alpha$ close to $\alpha^{*}$. Also, by continuity, if $\alpha$ slightly changes from $\alpha^{*}$, the system (18)-(19) still has a unique steady state solution close to $\left(K^{*}, L^{*}\right)$. Therefore, using differential analysis we can study how $K^{*}, L^{*}$ as well as $X^{*}$ and $V^{*}$ change when $\alpha$ is slightly increased from $\alpha^{*}$. The following proposition summarizes the main

\footnotetext{
${ }^{29}$ This result is shown in the Appendix of Proposition 4 below. The expression of $\sigma_{1}$ is given in Proposition 2.

${ }^{30}$ In this case the value of $X$ at the competitive market equilibrium is greater than its golden rule value (i.e the value of $X$ such that the marginal productivity of capital in the economy is identical to one).

${ }^{31}$ Indeed, these reasonings are frequently used in our current days where some point as the cause of unemployment the use of too much capital.
} 
results.

Proposition 4 Consider fixed values for the parameters $a, A, v$ and $\beta$. For a given $\alpha=\alpha^{*}$ let $\left(K^{*}, L^{*}\right)$ be a steady state solution of (18)-(19), and $s_{L}$ the corresponding labour share. Then, a slight decrease in $\alpha$ (increase in union power) from $\alpha^{*}$, increases $L^{*}, X^{*}$ and the corresponding utility of an employed worker if and only if $\sigma_{\left(X^{*}\right)}>\max \left(\sigma_{2}, \sigma_{3}\right)$ where:

$$
\sigma_{2}=\frac{\left(1-s_{L}\right)^{2}}{(1-\beta)\left(\alpha^{*}-1+s_{L}\right)-\left(2-\beta-s_{L}\right) v \alpha^{*}} \text { and } \sigma_{3}=1-\frac{\alpha^{*} s_{L}}{(2-\beta)\left(\alpha^{*}-1+s_{L}\right)+\left(1-\alpha^{*}\right)\left(2-\beta-s_{L}\right)}
$$

\section{Proof. See the Appendix.}

It is also easy to check that, under these conditions, an increase in union power implies an increase in $C_{2}$, i.e. the level of utility of those born old. Therefore, contrary to conventional wisdom, these results imply that an economy with unions may have at the steady state a better economic performance than an economy with a perfectly competive labour market. ${ }^{32}$ For this to be true $\sigma_{\left(X^{*}\right)}$ must satisfy simultaneously the folowing conditions: $\sigma_{\left(X^{*}\right)}>\sigma_{2\left(\alpha^{*}=1\right)}=\left(1-s_{L}\right)^{2} /\left[(1-\beta) s_{L}-\left(2-\beta-s_{L}\right) v\right]$ and $\sigma_{\left(X^{*}\right)}>\sigma_{3\left(\alpha^{*}=1\right)}=(1-\beta) /(2-\beta)$.

Note that, although Proposition 4 requires values of the elasticity of substitution between capital and labour sufficiently high, it holds for values of $\sigma$ below one. See, as an example, Figure 2 where we have depicted in the plane $(\alpha, \sigma)$ the $\sigma_{2}$ and $\sigma_{3}$ lines, for $s_{L}=0.64, \beta=0$, and $v=0.01$.

\section{(insert Figure 2 here)}

Let us explain why a sufficiently high value for $\sigma$ is required in order that unions may have a positive effect on welfare. Workers are able to obtain higher wages when union power increases. See (5). Facing an increase in the relative price of labour, producers will tend to favour the use of capital and increase X, due to a substitution effect. Obviously, this effect will be higher the higher the elasticity of substitution between capital and labour, $\sigma$. Also the rise in the marginal productivity of labour obtained when $\mathrm{K}$ increases

\footnotetext{
${ }^{32}$ However, as already explained, this result should not surprise us. On the one hand the golden rule is not necessarily satisfied in OLG models. On the other hand, since there are externalities, we are not in a first best environment. In this case, as it is well known, the introduction of another distortion (unions) is not necessarily a "bad thing".
} 
is higher the higher is $\sigma$. This positive shift in the marginal productivity of labour favours a rise in employment that offsets a possible increase in the reservation wage. ${ }^{33}$ See Figure 1 . Finally it is easy to check that the utility of those employed is an increasing function of the union's mark-up $(W / \bar{W})$. See (14) and (15). As already refered, this mark-up depends positively on unions bargaining power. See (4) and (5). However, it also depends on the ratio between the marginal contributions of capital and labour for output, which may decrease with increases in X. Nevertheless this decrease will be small for suficiently high values of $\sigma$.

\section{Local dynamics and bifurcation analysis}

In this section we study the influence of unions bargaining power $(1-\alpha)$ and increasing returns $(v)$ on the emergence of deterministic or stochastic (sunspots) endogenous fluctuactions, i.e. non-explosive fluctuations driven by self-fulfilling volatile expectations. ${ }^{34}$

In order to do this we shall use a geometrical method, as developed in Grandmont et al. (1998). This method, based solely on the values of the relevant parameters, elasticities and shares at the steady state, provides a full characterization of the emergence of endogenous fluctuations (deterministic and stochastic) near a steady state.

The first step of the geometrical method is to consider the linearised dynamics of the system (16)-(17) around a steady state and its associated Jacobian matrix. Using (8) and (24) the Jacobian matrix can be written

\footnotetext{
${ }^{33}$ For small values of $v$, when $X$ increases following an increase in union power, we obtain a reduction in $r$, that in turn induces a rise in the reservation wage. See (7) and (15). However, when externalities are important, i.e. $v$ big, the increase in $K$ may imply a rise in the marginal productivity of capital, so that $r$ also increases. In this case the reservation wage falls, and therefore employment unambiguosly increases with union power. Note that in order to obtain a positive effect on employment we must have $\sigma>\sigma_{2}$, and that $\sigma_{2}<0$ for $v$ high enough. See Proposition 4 and the Appendix.

${ }^{34}$ Note that in our model there is one predetermined variable $\left(K_{t}\right)$ and one nonpredetermined variable $\left(L_{t}\right)$, whose equilibrium value depends on the state of worker's expectations. More precisely, workers expectations about the future real rental cost of capital affect the equilibrium amount of labour (given a predetermined value for $K_{t}$ ) through its influence on the reservation wage.
} 
as: $^{35}$

$$
J=\left[\begin{array}{cc}
J_{K K} & J_{K L} \\
J_{L K} & J_{L L}
\end{array}\right]
$$

with:

$$
\begin{aligned}
J_{K K}= & v+\frac{1-s_{L}}{\alpha \sigma s_{L}}\left[(1-\alpha)(\sigma-1)+s_{L}\right] \\
J_{K L}= & \frac{K}{L}\left\{1+v-J_{K K}\right\} \\
J_{L K}= & \frac{L}{K}\left\{-J_{K K} \frac{\sigma \alpha v-\left(\alpha-1+s_{L}\right)}{\left(\alpha-1+s_{L}\right)}\right. \\
& \left.+\frac{1}{(\beta-1)} \frac{\sigma \alpha v+1-s_{L}}{\left(\alpha-1+s_{L}\right)}\right\} \\
J_{L L}= & -J_{K L} \frac{L}{K} \frac{\sigma \alpha v-\left(\alpha-1+s_{L}\right)}{\left(\alpha-1+s_{L}\right)} \\
& -\frac{1}{(\beta-1)} \frac{\left(1-s_{L}\right)}{\left(\alpha-1+s_{L}\right)}
\end{aligned}
$$

where $v, \sigma$ and $s_{L}$ represent respectively the elasticity of the capital externality, the elasticity of substitution between capital and labour in production and the labour share of output, all evaluated at the considered steady state solution; $(1-\alpha)$ is the union bargaining power and $\beta$ the propensity to consume when young. Moreover recall that $v>0, \sigma \geq 0,1>s_{L}>1-\alpha, 0 \leq$ $(1-\alpha)<1$ and $0 \leq \beta<1$.

In order to simplify the analysis, and as this assumption does not change in any significant way the results, we will assume for the remainder of the paper that $\beta=0$, i.e. that the young generation does not consume and fully devotes its labour income to savings. The trace and the determinant of $J$ as a function of the relevant "parameters" of the model, for $\beta=0$, are then given by:

$$
\begin{aligned}
& T=T_{1}+T_{2} \sigma \\
& D=D_{1}+D_{2} \sigma
\end{aligned}
$$

\footnotetext{
${ }^{35}$ Note that we continue to consider that $\varepsilon_{\Psi, L}=0$ and $\varepsilon_{\Psi, K}=\nu>0$.
} 
where:

$$
\begin{aligned}
& D_{2}=-T_{2}=\frac{v}{s_{L}} \\
& T_{1}=\frac{v\left(\alpha-1+s_{L}\right)+\alpha s_{L}}{s_{L}\left(\alpha-1+s_{L}\right)} \\
& D_{1}=\frac{\left[v(1-\alpha)+s_{L}\right]\left(1-s_{L}\right)}{s_{L}\left(\alpha-1+s_{L}\right)} .
\end{aligned}
$$

$T_{1\left(\alpha, v, s_{L}\right)}$ and $D_{1\left(\alpha, v, s_{L}\right)}$ define respectively the values taken by $T$ and $D$ when $\sigma=0$. Note that the trace and the determinant of $J$ correspond respectively to the sum and product of its eigenvalues, i.e. the roots of the associated characteristic polinomial $Q(\lambda) \equiv \lambda^{2}-\lambda T+D$.

The basic idea of the method is to fix all parameters except one, the bifurcation parameter, and to analyse how the relationship between $D$ and $T$ evolves in the plane $(T, D)$ as this parameter continuously change. In our case we chose $\sigma$ as our bifurcation parameter. From (29) and (30), the locus $\left(T_{(\sigma)}, D_{(\sigma)}\right)$ is defined through the following expression $(\Delta$ line):

$$
D=\Delta(T)=\left(D_{1}-\frac{T_{1}}{T_{2}} D_{2}\right)+\frac{D_{2}}{T_{2}} T
$$

$>$ From the above expressions it is easy to see that the expression $\Delta$ is linear and negatively sloped:

$$
\Delta^{\prime}=\frac{D_{2}}{T_{2}}=-1
$$

Given that $\sigma \geq 0$, only part of the $\Delta$ line is relevant to our analysis. That is the part begining at $\left(T_{1}, D_{1}\right)$ when $\sigma=0$ and ending at $(-\infty,+\infty)$ for $\sigma=+\infty$. This half-line $\Delta$, represented in the space $(T, D)$, points upwards to the left. See an example in figure 3.

(insert Figure 3 here)

To proceed with the geometrical method it is convenient to define in the plane $(T, D)$ the following lines. The line $A C(D=T-1)$ where a 
local eigenvalue is equal to 1 ; the line $A B(D=-T-1)$, where one eigen value is equal to -1 ; and the segment $B C(D=1$ and $|T|<2)$ where two eigenvalues are complex conjugates of modulus 1 . See figure 3 . These lines divide the plane $(T, D)$ into three different regions: sink, source and saddle $e^{36}$, according to the values assumed by the local eigenvalues of the system and the respective dynamic properties near the steady state. ${ }^{37}$

Using our half-line $\Delta$, as in figure 3 , we can identify whether the steady state is a sink, a saddle or a source, depending on the values taken by $\sigma$. If the steady state is a saddle or a source it is locally determinate. When the steady state is a sink the system is locally indeterminate. ${ }^{38}$ As shown in Grandmont et al. (1998) in this case there are infinitely many stochastic equilibria, driven by stochastic self-fulfilling expectations (sunspots), in an arbitrarily small neighbourhood of the steady-state. If the system were linear this would be the only possibility for the emergence of endogenous fluctuations. However, in non linear systems deterministic and stochastic endogenous fluctuactions around a steady state may also emerge due to the ocurrence of local bifurcations. ${ }^{39}$

A local Hopf bifurcation generically occurs, when by slightly changing a parameter of the model, the values of $T$ and $D$ cross the interior of the segment $B C$ (i.e. the bifurcation parameter crosses a certain value $\sigma_{H}$ ). In this case, for some values of $\sigma$ close enough to $\sigma_{H}$, there are deterministic trajectories lying over an invariant closed curve surrounding the stationary state in the state space (deterministic endogenous fluctuactions defined by periodic or

\footnotetext{
${ }^{36}$ The system is locally stable $a$ sink (the two local eigenvalues have modulus less than 1 ) if and only if the point $(T, D)$ lies in the interior of the triangle $A B C$. The stationary state is a source when both eigenvalues have modulus higher than one. It is a saddle in all other cases. For more details see Azariadis (1993).

${ }^{37}$ Note that we are using the linear map associated to the matrix $J$ to study the local stability properties of the steady state. This procedure is valid for non linear systems as long as $J$ is invertible and no eigenvalue crosses the unit circle (Hartman-Grobman Theorem, see for instance Grandmont (1988) pg 28, Theorem B.4.1 or Azariadis (1993), pg 59, Theorem 6.1).

${ }^{38}$ Indeterminacy occurs when the number of eigenvalues strictly lower than one in absolute vale is larger than the number of predetermined variables. Here, this means that for a given initial condition of the predetermined variable $K_{t}$, close to the steady state, there is a continuum of values for $L_{t}$ defining equilibrium paths that converge to the steady state.

${ }^{39} \mathrm{~A}$ bifurcation occurs when, by slightly changing one parameter of the model, there is a qualitative change in the dynamic properties of the equilibrium trajectories nearby the steady state. For a more technical approach the reader may wish to consult Grandmont (1988) or Hale and Koçak (1991).
} 
quasi-periodic orbits). Moreover, if the steady state is determinate, stochastic endogenous fluctuactions may also emerge when these bifurcations are supercritical. ${ }^{40}$ Indeed, in this case, there are infinitely many non-explosive stochastic equilibria (sunspots), with a compact support containing in their interior the invariant closed curve (Hopf), as shown in Grandmont et al. (1998).

A flip bifurcation occurs when the values of $T$ and $D$ cross the $A B$ line, and a deterministic cycle of period two nearby a steady state emerges. ${ }^{41}$ This will not be possible in our model, since the half-line $\Delta$ is paralel to the line $A B$.

Finally, when the values of $T$ and $D$ cross the $A C$ line, and if Propositions 1 and 3 are satisfied, a transcritical bifurcation occurs. ${ }^{42}$ In this case there are two steady states exchanging stability properties. When the transcritical occurs in the interior of segment $A C$ one steady state is a saddle and the other is a sink. This means that nearby a determinate steady state (saddle) there is a indeterminate one (sink), and therefore lots of stochastic endogenous fluctuations around it.

\subsection{The role of unions bargaining power}

Back to our dynamic system we shall now discuss how the the half-line $\Delta$ moves in the space $(T, D)$ as $\alpha$ varies from $\left(1-s_{L}\right)$ to $1 .^{43}$ This amounts to analyse how the origin $\left(T_{1\left(\alpha, v, s_{L}\right)}, D_{1\left(\alpha, v, s_{L}\right)}\right)$ of the half-line $\Delta$ changes with $\alpha$, since its slope, as we have seen, is constant (equal to -1 ).

$>$ From now on, and for an exposition device let us fix relevant ranges for

\footnotetext{
${ }^{40}$ If the Hopf bifurcation is supercritical this means that the invariant closed curve emerges when the steady state becomes a source (determinate). Bifurcations are supercritical or subcritical depending on the values of higher order derivatives of the dynamic system. Since this implies complex analitical computations, the usual procedure is instead to check by simulations what kind of bifurcation occurs.

${ }^{41}$ It is also possible to construct infinitely many stochastic endogenous fluctuations within a compact neighbourhood of the steady state, containing the cycle of period two, if the flip is supercritical and occurs when $T$ and $D$ cross the interior of the segment $A B$. In this case the cycle of period two emerges when the steady state is a saddle (determinate).

${ }^{42}$ When $T$ and $D$ cross the line $A C$ other types of bifurcations may occur (pitchfork or saddle-node). However, since we have assumed the existence of at least one steady state (Proposition 1) and at most of two (Proposition 3) these other bifurcations are rulled out.

${ }^{43}$ Remember that, by construction of the model, we must have $\left(1-s_{L}\right)<\alpha \leq 1$. See (3) and (8).
} 
our paramaters $\alpha, s_{L}$ and $v$ :

Assumption $2\left(1-s_{L}\right)<\alpha \leq 1,1 / 2<s_{L}<1$ and $0<v<2\left(2 s_{L}-1\right) .{ }^{44}$

First note that $T_{1\left(\alpha, v, s_{L}\right)}$ and $D_{1\left(\alpha, v, s_{L}\right)}$ are always positive and that both decrease with $\alpha$. Indeed $\left(T_{1}, D_{1}\right)$ take the values $(+\infty,+\infty)$ for $\alpha=1-s_{L}$ and $\left((v+1) / s_{L},\left(1-s_{L}\right) / s_{L}\right)$ for $\alpha=1$. Furthermore the locus $\left(T_{1(\alpha)}, D_{1(\alpha)}\right)$ lies over an half line $\Delta_{1}$ whose expression is given as follows:

$$
\begin{aligned}
D_{1} & =\Delta_{1}\left(T_{1}\right)=T_{1}(1+v)-\frac{v}{s_{L}}(2+v)-1 \\
\text { for } \quad T_{1} & \in\left((v+1) / s_{L},+\infty\right)
\end{aligned}
$$

This half line $\Delta_{1}$ is easily obtained solving (32) for $\alpha$ and substituting it in (33). See figure 4 where we represent an example of the half line $\Delta_{1}$.

(insert figure 4 here)

The slope of the half line $\Delta_{1}$ is greater than 1 since $v>0$. It is also easy to check that $\left(T_{1(\alpha)}, D_{1(\alpha)}\right)$ is a point in the space $(T, D)$ lying to the left of line $A C(D=T-1)$, for $\left(1-s_{L}\right)<\alpha<\alpha_{a}$, and to the right of the line $A C$ for $\alpha_{a}<\alpha<1$ where:

$$
\alpha_{a}=\frac{2\left(1-s_{L}\right)}{\left(2-s_{L}\right)}
$$

For $\alpha=\alpha_{a}$ the point $\left(T_{1(\alpha)}, D_{1(\alpha)}\right)$ lies exactly on the $A C$ line. Moreover, substituting $\alpha$ by $\alpha_{a}$ in expressions (32) and (33) we see that $T_{1\left(\alpha_{a}\right)}>2$ and $D_{1\left(\alpha_{a}\right)}>1$, since $v>0$. Therefore the half line $\Delta_{1}$, with a slope greater than 1 , must cross the line $A C$ above point $C$. See figure 4 where we have also represented the half line $\Delta$ for $\alpha=\alpha_{a}$. Note also that since $T_{1}$ and $D_{1}$ are decreasing functions of $\alpha$, the half line $\Delta$ does (not) cross the line AC for $\alpha>\alpha_{a}\left(\alpha<\alpha_{a}\right)$.

\footnotetext{
${ }^{44}$ The first inequality follows from (8). Note also that this assumption does not impose strange values neither on the labour share nor on capital externalities. Indeed empirical evidence points to values of $s_{L}$ higher than $1 / 2$ and for small values of $v$. Moreover, this assumption simplifies considerably our analysis, as it will become apparent below.
} 
Consider now the critical value $\alpha=\alpha_{b}$ such that half-line $\Delta$ crosses point C. Substituting (31), (32) and (33) in (34) we obtain:

$$
\alpha_{b}=\frac{4\left(1-s_{L}\right)}{2-v} .
$$

Note that under Assumption 2, $v<2\left(2 s_{L}-1\right)$, so that $\alpha_{b}<1$. Also, since $v>0, \alpha_{a}<\alpha_{b}$. Moreover, using (33), we have that $0<D_{1(\alpha=1)}<1$. Therefore, since $T_{1(\alpha)}, D_{1(\alpha)}$ are decreasing with $\alpha$, the half-line $\Delta$ for $\alpha=1$ must be of the type represented in figure 3. Also for $\alpha>\alpha_{b}$ the half-line $\Delta$ crosses the segment $B C$ in its interior. The folowing lemma summarizes these results.

Lemma 1 Consider Assumption 2. Then, the slope of the half line $\Delta_{1}$ is greater than 1. The half line $\Delta_{1}$ crosses the line $A C$ for $\alpha=\alpha_{a}$ with $T_{1}>2$ and $D_{1}>1$. The half line $\Delta$ does (not) cross the line $A C$ for $\alpha>\alpha_{a}\left(\alpha<\alpha_{a}\right)$. Also for $\alpha>\alpha_{b}\left(\alpha<\alpha_{b}\right)$ the half-line $\Delta$ does (not) cross the segment $B C$ in its interior. Moreover $\alpha_{b}>\alpha_{a}$.

We can now see geometrically how the half line $\Delta$ moves as $\alpha$ decreases from 1 to $\left(1-s_{L}\right)$. See figure 4 . As $\alpha$ decreases the half line $\Delta$ shifts in a paralel way (remember that its slope is -1 ), to the right, with initial points moving upwards along the half line $\Delta_{1}$.

Combining now all these results we can state that in our model flip bifurcations are always ruled out. That is to say that the half-line $\Delta$ never crosses the line $A B$. However, Hopf bifurcations are possible, since the half-line $\Delta$ crosses the interior of segment BC when $\alpha>\alpha_{b}$. Moreover transcritical bifurcations also occur since the half-line $\Delta$ intersects the line $A C$ for $\alpha_{a}<\alpha<1$. By straightforward calculations we can obtain the values of $\sigma$ such that the half-line $\Delta$ intersects the $A C$ and $B C$ lines, respectively $\sigma_{T}$ and $\sigma_{H}$ :

$$
\begin{aligned}
\sigma_{T} & =1-\frac{\alpha s_{L}}{2\left(\alpha-1+s_{L}\right)} \\
\sigma_{H} & =\frac{\alpha\left[s_{L}+v\left(1-s_{L}\right)\right]-\left(1-s_{L}\right)\left[2 s_{L}+v\right]}{v\left(\alpha-1+s_{L}\right)}
\end{aligned}
$$

The following proposition summarises the results on local stability and bifurcation analysis, that can now be immediately obtained by inspection of figure 4 . 
Proposition 5 Given fixed values for $v$ and $s_{L}$ satisfying Assumption 2 it follows from Lemma 1 that the following generically holds:

(i) for $\left(1-s_{L}\right)<\alpha<\alpha_{a}$ the steady state is always a source.

(ii) for $\alpha_{a}<\alpha<\alpha_{b}$; the steady state is a saddle when $0<\sigma<\sigma_{T}$; undergoes a transcritical bifurcation for $\sigma=\sigma_{T}$ becoming a source for $\sigma>\sigma_{T}$.

(iii) for $\alpha_{b}<\alpha<1$; the steady state is a saddle when $0<\sigma<\sigma_{T}$; undergoes a transcritical bifurcation for $\sigma=\sigma_{T}$ becoming a sink for $\sigma_{T}<$ $\sigma<\sigma_{H}$; undergoes a Hopf bifurcation for $\sigma=\sigma_{H}$ becoming a source for $\sigma>\sigma_{H}$.

This means that for $\alpha>\alpha_{b}$ deterministic and stochastic endogenous fluctuations may emerge. When a transcritical bifurcation occurs two steady states coexist (for $\sigma$ close to $\sigma_{T}$ ) one being a saddle and the other a sink (indeterminate). Hence there are infinitily many stochastic endogenous fluctuations arbitrarily near the sink. As $\sigma$ is increased, a steady-state which was a sink, becomes a source, and a Hopf bifurcation occurs, generating deterministic periodic or quasiperiodic dynamics around the steady state. In the simulations we performed the Hopf bifurcation was supercritical, the invariant closed curve emerging for values of $\sigma$ such that the steady-state is a source (determinate). In this case, as refered above, there are lots of stochastic endogenous fluctuations whose compact support contains the invariant close curve. Therefore, even when the local steady state under analysis is determinate (saddle or source) endogenous fluctuations emerge in our model if $\sigma$ is close enough to the sink boundaries $\left(\sigma_{T}\right.$ and $\left.\sigma_{H}\right)$.

The above findings on local stability, bifurcations and the emergence of endogenous fluctuations are depicted in figure 5. There, for given values of $v>0$ and $s_{L}$ satisfying Assumption 2, we have plotted $\sigma_{T}$ and $\sigma_{H}$ as functions of $\alpha$. Note that both $\sigma_{T}$ and $\sigma_{H}$ increase with $\alpha$. For $\alpha=\alpha_{a}$ we have $\sigma_{T}=0$ and for $\alpha=1$ we have $\sigma_{T}=0.5$ and $\sigma_{H}=\left(2 s_{L}-1\right) / \nu>0.5 .^{45}$ Moreover for $\alpha=\alpha_{b}$ we have that $\sigma_{T}=\sigma_{H}$.

(insert Figure 5 here)

\subsection{The role of externalities}

Proposition 5 summarizes the results on local stability and on the occurrence of bifurcations if Assumption 2 is satisfied. Therefore it only applies as long

\footnotetext{
${ }^{45}$ Note that, under Assumption $2,\left(2 s_{L}-1\right) / \nu$ may even be greater than one.
} 
as there is some degree of capital externalities $(v>0)$. Since it is a point often made that externalities may exist but in a low degree, an interesting question is to know how the results stated before, in Proposition 5, change as $v$ decreases approaching zero.

$>$ From (38) we can see that the line $\sigma_{H}$ plotted in figure 5 shifts upwards ( $\alpha_{b}$ decreases) when $v$ diminishes. Hence higher values of $\sigma$ (and lower values of $\alpha$ ) are required for the ocurrence of a Hopf bifurcation when externalities are lower. Since $\lim _{v \rightarrow 0} \sigma_{H}=\infty$ we may suspect that the existence of externalities (even if only by an infinitesimal amount) is a necessary condition for the ocurrence of Hopf bifurcations. This is indeed the case. With constant returns to scale (i.e. no externalities, $v=0$ ) from $(29)-(33)$ we have $T_{2}=D_{2}=0$. Note also that as $T=T_{1\left(\alpha, v=0, s_{L}\right)}$ and $D=D_{1\left(\alpha, v=0, s_{L}\right)}$ the trace and the determinant do not depend on $\sigma$. Moreover we have that $D=T-1$. This means that the relation between $T$ and $D$ coincides with the $A C$ line. Therefore one of the two eigenvalues is always equal to one. The other eigenvalue is always positive, higher than one if $\left(1-s_{L}\right)<\alpha<2\left(1-s_{L}\right)$, or lower than one if $2\left(1-s_{L}\right)<\alpha<1$. Hence in the CRS model Hopf and flip bifurcations can not occur i.e. local deterministic endogenous fluctuations, preserved under slight changes of the parameters, do not exist. However, when $2\left(1-s_{L}\right)<\alpha<1$ infinitely many stochastic endogenous fluctuations, in a arbitrarily small neighbourhood of the steady state, may emerge. Indeed in the CRS case the dynamic system under study collapses into a one dimensional dynamic function for $X_{t}$ (see (17)). This means that local indeterminacy will emerge when its eigenvalue is lower than one i.e. if $2\left(1-s_{L}\right)<\alpha<1$. These results are summarized in the following proposition.

\section{Proposition 6 The CRS economy}

In the CRS case the dynamic system under study collapses into a one dimensional dynamic function for $X_{t}$. Its eigenvalue is always positive, higher than one if $\left(1-s_{L}\right)<\alpha<2\left(1-s_{L}\right)$, or lower than one (locally indeterminate) if $2\left(1-s_{L}\right)<\alpha<1$. Deterministic local endogenous fluctuations (stucturally stable) do not occur.

\subsection{Discussion of the results}

In this subsection we interpret and discuss the results stated in Propositions 5 and 6 . First of all we have seen that externalities are necessary for the emergence of local deterministic endogenous fluctuations. The rationale 
for this result has to do with the fact that without externalities local deterministic trajectories can not be non monotonic. To illustrate this point consider the case of the CRS economy. Suppose that the economy is at its steady state solution for some time and that, for some reason, the expected rental cost of capital, $r_{t+1}$, increases by a small amount. Then, (see (15)) the reservation wage decreases, and therefore from (4) $X_{t}$ also decreases. Under perfect foresight $r_{t+1}$ has to increase and in the absence of externalities this is only possible if $X_{t+1}$ further decreases (see (7)). Hence the existence of non monotonic deterministic trajectories near the steady state is not possible.

On the contrary, with capital externalities, an increase in $r_{t+1}$ correctly foreseen, may be accompanied by an increase in $X_{t+1}$ if $K_{t+1}$ also increases. For this to be possible savings (the wage bill) in period $t$ must rise following the expected increase in $r_{t+1}$. As we have seen, this rise in $r_{t+1}$ implies a decrease in $X_{t}$, which given a predetermined value of $K_{t}$ implies an increase in $L_{t}$. Hence, local non monotonic equlibria trajectories may exist if the wage bill is an increasing function of $L_{t}$ near the steady state i.e: $\sigma / \alpha>X f^{\prime}(X) / f(X)$. Moreover, the lower the degree of capital externalities the more $K_{t+1}$ has to increase, after the rise in a correctly foreseen $r_{t+1}$, in order that deterministic endogenous fluctuactions occur. This means that savings have to increase more implying a higher value for $\sigma$. This explains the upward shift of the line $\sigma_{H}$ (figure 5) when $v$ diminishes, as refered in the last section.

Another result worth discussing concerns the role of unions bargaining power for the emergence of Hopf bifurcations and indeterminacy. Note that for a positive $v$, even for $\alpha=1$, the condition $\sigma / \alpha>X f^{\prime}(X) / f(X)$ may be satisfied for sufficiently high values of $\sigma$. Of course if $\alpha<1, \sigma$ may be lower, since the existence of unions bargaining strenght tends to dampen the fall in the wage bill that might occur when employment increases with a given value for $K$. For example, from (38) we can see that for values of $\sigma$ around one and for low values of the externality $\left(v<2 s_{L}-1\right)$ a Hopf bifurcation occurs for $\alpha<1$. See also figure 5. This means that, although the existence of union bargaining power is not necessary for the ocurrence of Hopf bifurcations it may increase its likelihood, for empirically plausible values of the other parameters.

Also, by direct inspection of figure 5 we see that, for a fixed value of $\sigma$, an increase in unions bargaining power reduces the scope for local indeterminacy. However, it creates potential instabilities as the steady state becomes a source. Suppose that for a given $\sigma,(1-\alpha)$ is big enough, so that the steady state is a source. Assume further that for some "miraculous" reason 
the economy is at the steady state. Then, if there is an exogenous shock the economy may face severe adjustment problems. The equilibrium trajectories may become explosive, or explosiveness may become contained due to the existence of an attracting invariant closed curve (supercritical Hopf). Nevertheless the economy would never recover its stationary state.

Finally, we may wonder whether unions are good or bad institutions from a social welfare point of view. As we have seen in section 3 , for plausible values of the parameters, if the steady state is the relevant solution then unions may be a good idea: employment, capital and workers' welfare may be higher at the steady state in this case. However, we should be careful in our conclusions, since indeterminacy and the existence of deterministic fluctuactions may reduce the scope to consider the steady state as the relevant solution. If the existence of unions facilitates the emergence of endogenous fluctuations, then social welfare may indeed decrease. Along a trajectory exhibiting endogenous fluctuations around a steady state, there might be fortunate generations with higher levels of welfare. However other generations will suffer. Therefore there may exist an intergenerational equity argument against the existence of unions.

\section{Concluding Remarks}

In this paper we analyse the economic role of unions with respect to steady state equilibria and with respect to local dynamics. We consider an overlapping generations economy with increasing returns to scale due to positive production externalities. We also consider endogenous labour supply decisions (indivisible labour) and endogenous capital accumulation. As we have seen, a slight increase in unions power may increase the utility levels of all agents in an economy at the steady state. However multiple steady states may exist. Moreover, endogenous fluctuations may emerge, either due to local indeterminacy or to the occurrence of Hopf bifurcations. The scope for local indeterminacy may be reduced, but Hopf bifurcations may become more likely when unions are present. If the relevant trajectory exhibits endogenous fluctuations, the steady state welfare is no longer the unique important element from a social point of view. In this case, whether unions are 'good' institutions or not may well depend on the trade off between efficiency and intergenerational equity that society is willing to take.

Some extensions of our analysis or further development of the model 
considered may be desirable. In our OLG economy capital accumulation is obtained out of wages. Since usually workers are able to obtain higher wages when unions are present, some of our results are not completely surprising. The consideration of a Woodford type of model, where due to financial constraints only capitalists invest, or a model where agents have infinite horizon may bring some different results, at least from the steady state point of view. Another desirable extension of our model is the consideration of more general preferences. With a Cobb Douglas utility function savings do not depend on the interest rate. And the savings behaviour may be quite important not only for the dynamics of the model but also for the capital level at the steady state. Another interesting study would be to understand whether certain stylised economic policy rules are able to eliminate endogenous fluctuations (at least locally) in the presence of unions.

However, this work has shown that unions may have important effects on economic performance, not only from a positive point of view but also from a normative point of view. Therefore we believe that further research on this subject is much welcome.

\section{A Appendix}

\section{A.1 Proof of Proposition 4}

Proof. We start by analysing the effects of $\alpha$ on $X$. Differentiating (22) and using (8) and (24) we have that:

$$
\varepsilon_{X, \alpha}=-\frac{\left(2-\beta-s_{L}\right)}{(1-\beta) s_{L}} \frac{1}{H(X)}
$$

so that $X$ is decreasing in $\alpha$, i.e. increasing in union power, for $\sigma>\sigma_{1}$ given in Proposition 2. Note that $\sigma_{1}<1$.

We turn now to the effects of $\alpha$ on capital. Differentiating (18) we have that:

$$
v \varepsilon_{K, \alpha}=\frac{\left(1-s_{L}\right)}{s_{L}}+\frac{\left(\alpha-1+s_{L}\right)\left(\sigma-1+s_{L}\right)}{\alpha \sigma s_{L}} \varepsilon_{X, \alpha}
$$

This implies that we have $\varepsilon_{K, \alpha}<0$ together with $\varepsilon_{X, \alpha}<0$ if $\sigma>\max \left(\sigma_{1}, \sigma_{4}\right)$ where: 


$$
\sigma_{4}=\frac{\left(1-s_{L}\right)^{2}}{(1-\beta)\left(\alpha-1+s_{L}\right)} .
$$

For steady state employment, as we have that $\varepsilon_{L, \alpha}=\varepsilon_{K, \alpha}-\varepsilon_{X, \alpha}$, using (40) we obtain:

$$
v \varepsilon_{L, \alpha}=\frac{\left(1-s_{L}\right)}{s_{L}}+\frac{\left(\alpha-1+s_{L}\right)\left(\sigma-1+s_{L}\right)-v \alpha \sigma s_{L}}{\alpha \sigma s_{L}} \varepsilon_{X, \alpha}
$$

Therefore, steady state employment increases with union power, $(1-\alpha)$, together with $\varepsilon_{X, \alpha}<0$ if $\sigma>\max \left(\sigma_{1}, \sigma_{2}\right)$. Since $\sigma_{2}>\sigma_{4}, K, L$ and $X$ increase simultaneously with union power for $\sigma>\max \left(\sigma_{1}, \sigma_{2}\right)$.

Finally we analyse how the steady state utility of the representative employed individual varies with union power. Substituting (4), (5), and (15) in (14) we obtain:

$$
a+V(W, r)=a \frac{\left[f(X)-\alpha f^{\prime}(X) X\right]}{\left[f(X)-f^{\prime}(X) X\right]}=V^{*}(X) .
$$

Differentiating the previous expression we have that

$$
\varepsilon_{V^{*}, \alpha}=\frac{\left(1-s_{L}\right)}{s_{L}}\left\{\frac{(1-\alpha)}{\alpha} \frac{(\sigma-1)}{\sigma} \varepsilon_{x, \alpha}-1\right\} .
$$

Therefore, since $a$ is constant, $V$ is decreasing in $\alpha$, i.e. increasing in union power, when $\varepsilon_{V^{*}, \alpha}<0$. This happens for $\sigma>\sigma_{3}>\sigma_{1}$.

Combining now all the previous results Proposition 4 follows.

\section{References}

[1] Aloi, M., H. Dixon and T. Lloyd-Braga, (1998), " Endogenous Fluctuations in an Open Economy with Increasing Returns to Scale", forthcoming Journal of Economic Dynamic and Control.

[2] Arrow, K. J., (1962), "The Economic Implications of Learning-bydoing", Review of Economic Studies, 29. 
[3] Azariadis, C., (1993), Intertemporal Macroeconomics, Blackwell, Oxford.

[4] Bénassy, J. P., (1997), "Imperfect Competition, Capital Shortages and Unemployment Persistence", Scandinavian Journal of Economics, 99,15-27.

[5] Benhabib, J. and R. Farber, (1994), "Indeterminacy and Increasing Returns", Journal of Economic Theory, 63, 19-41.

[6] Caballero, R. and R. Lyons, (1990), "Internal versus External Economies in European Industry", European Economic Review, 34, 805-826.

[7] Cazzavillan, G., T. Lloyd-Braga and P. Pintus, (1998), "Multiple Steady States and Endogenous Fluctuations with Increasing Returns to Scale in Production", Journal of Economic Theory, 80, 60-107.

[8] Cazzavillan, G. and P. Pintus, (1998), "Indeterminacy and Endogenous Fluctuations in an OLG Economy with Productive Externalities", mimeo.

[9] Coimbra, R., (1999), "Expectations-Driven Business Cycles Under the Efficiency Wages Hypothesis", unpublished Ph.D. dissertation, University of York.

[10] d'Aspremont, C., R. Dos Santos Ferreira and L.-A. Gerard-Varet, (1995): "Market Power, Coordination Failures and Endogenous Fluctuactions", in H. Dixon and N. Rankin, eds., The New Macroeconomics: Imperfect Markets and Policy Effectiveness, Cambridge University Press, Ch.5, 94-138.

[11] Devereux, M. B. and B. Lockwood, (1991), "Trade Unions, Non-Binding Wage Agreements, and Capital Accumulation", European Economic Review, 35, 1411-1426.

[12] de Vilder, R., (1996), "Complicated Endogenous Business Cycles under Gross Substitutability", Journal of Economic Theory, 71, 416-442.

[13] Farmer, R. and J. T. Guo, (1994), "Real Business Cycles and the Animal Spirits Hypothesis", Journal of Economic Theory, 63, 42-72. 
[14] Galí, J., (1994), "Monopolistic Competition, Business Cycles, and the Composition of Aggregate Demand", Journal of Economic Theory, 63, 73-96.

[15] Grandmont, J. M., (1988), "Nonlinear Difference Equations, Bifurcations and Chaos: An Introduction", CEPREMAP Paper 8811 and IMSSS Economics Lectures Notes Series 5, Stanford University.

[16] Grandmont, J. M., P. Pintus and R. de Vilder, (1998), "Capital-Labour Substitution and Competitive Nonlinear Endogeous Business Cycles", Journal of Economic Theory, 80, 14-59.

[17] Grout, P. A., (1984), "Investment and Wages in the Absence of Binding Contracts", Econometrica,

[18] Hale, J. and H. Koçak, (1991), Dynamics and Bifurcations, SpringerVerlag, New York.

[19] Hamermesh, D. S., (1993), Labor Demand, Princeton University Press, Princeton, New Jersey.

[20] Hansen, G., "Indivisible Labor and the Business Cycle", Journal of Monetary Economics, 16, 309-325.

[21] Jacobsen, H. J., (2000), "Endogenous, Imperfectly Competitive Business Cycles", European Economic Review, 44, 305-336.

[22] Lloyd-Braga, T., (1995), "The Model with Capital: Increasing Returns to Scale and Endogenous Fluctuactions", Ph.D. Thesis (Ch. 2), Universidade Católica Portuguesa, Lisboa.

[23] Oswald, A. J., (1982), "The Microeconomic Theory of the Trade Union", Economic Journal, 92, 269-283.

[24] Pintus, P., (1997), "Indeterminacy and Expectations Driven Fluctuations with Variable Factor Utilization and Unemplyment", mimeo, CEPREMAP.

[25] Reichlin, P., (1986)," Equilibrium Cycles in an Overlapping Generations Economy with Production", Journal of Economic Theory, 40, 89-103. 
[26] Romer, P. M., (1986), "Increasing Returns and Long-Run Growth", Journal of Political Economy, 94.

[27] Sutton, J., (1986), "Non-Cooperative Bargaining Theory: An Introduction", Review of Economic Studies, 53.

[28] Woodford, M., (1986), "Stationary Sunspot Equilibria in a Finance Constrained Economy", Journal of Economic Theory, 40, 128-137. 


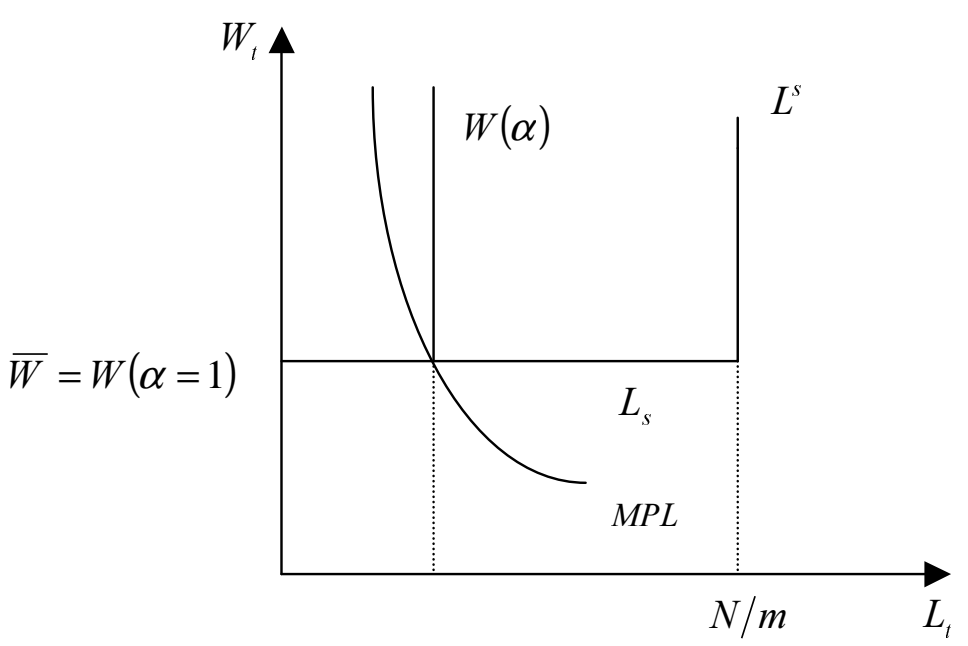

FIGURE 1 


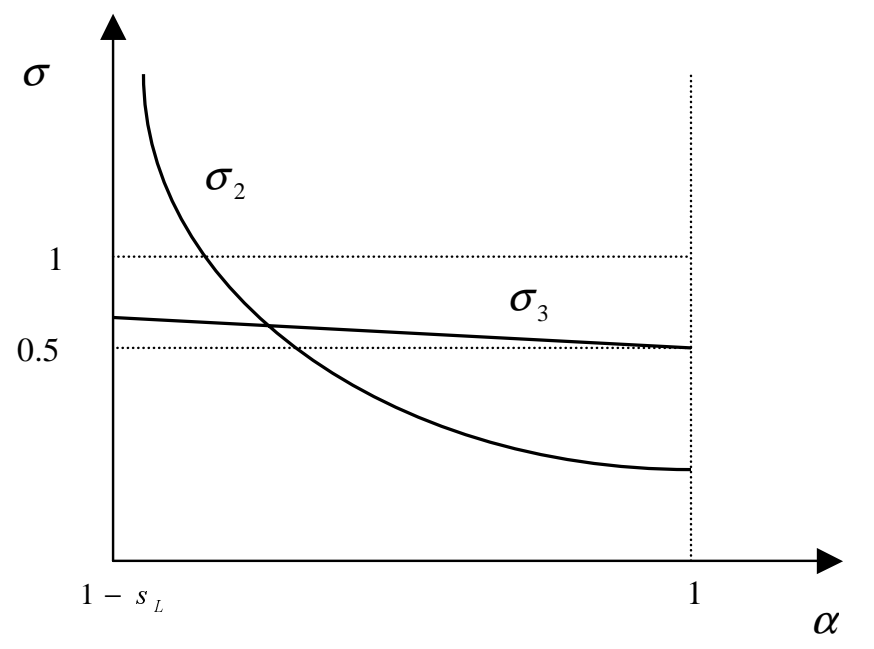

FIGURA 2 


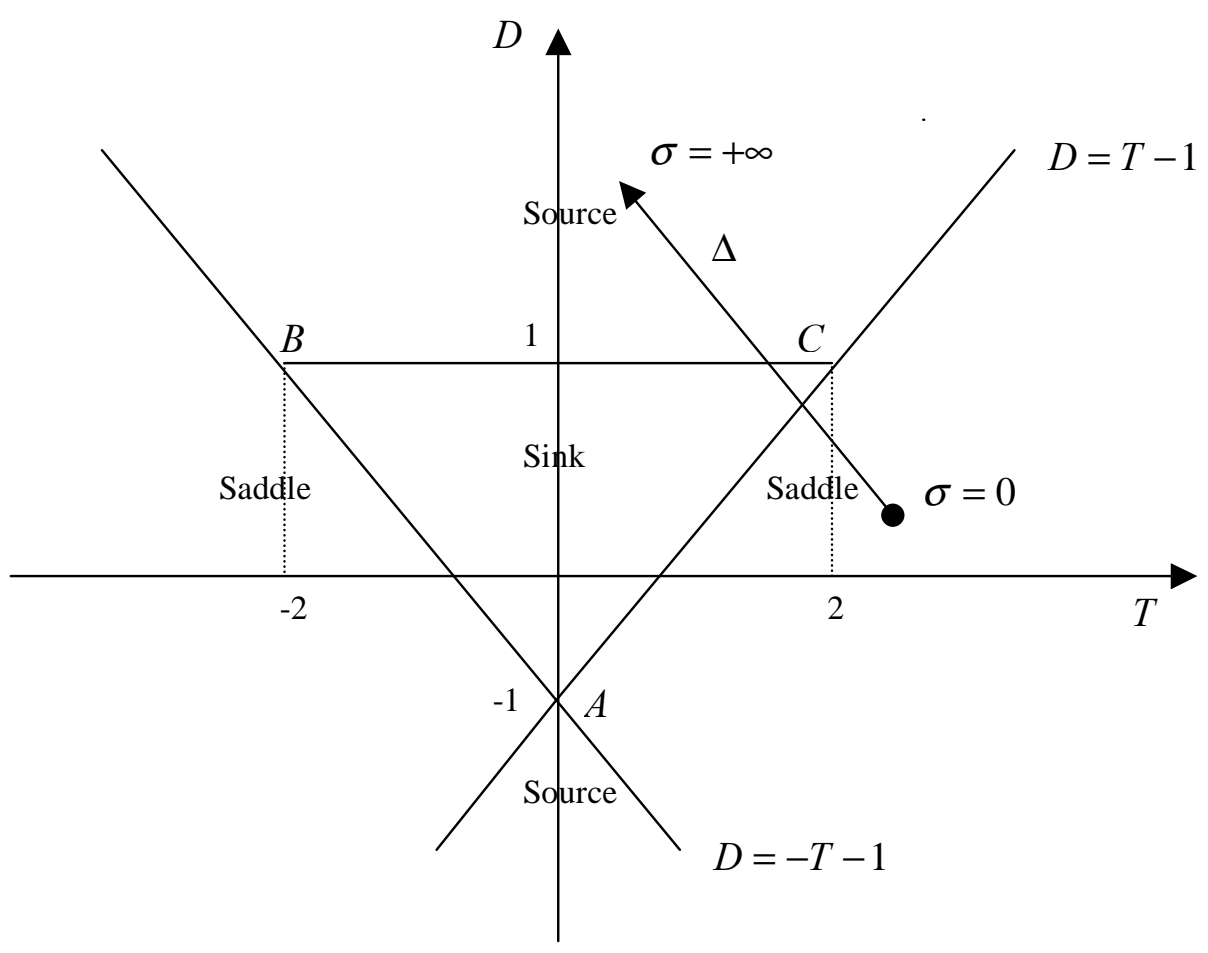

FIGURE 3 


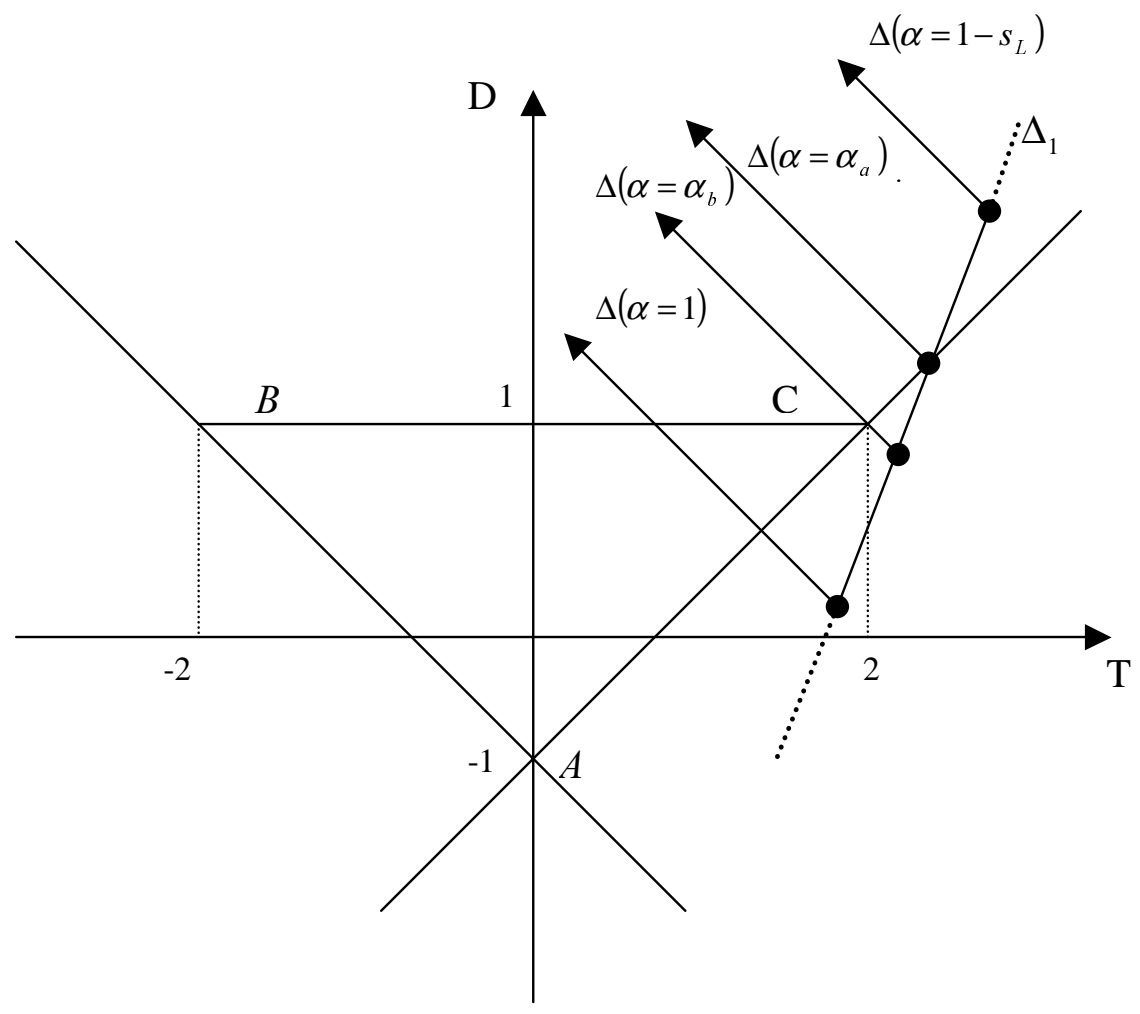

FIGURE 4 


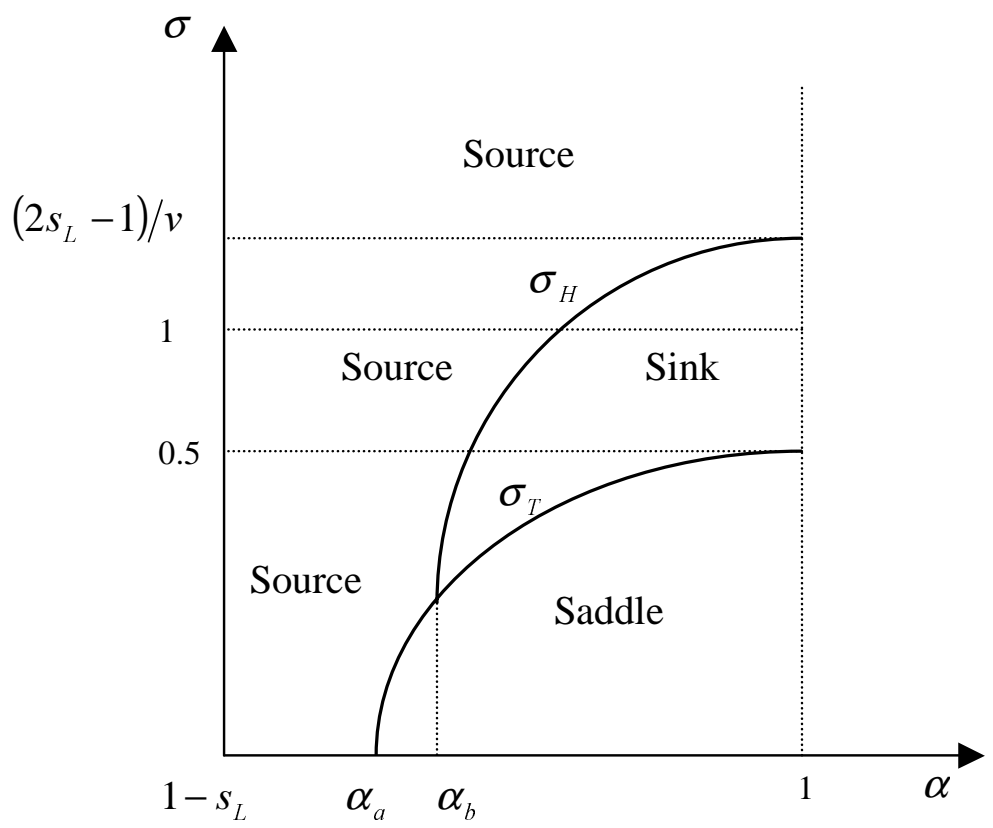

FIGURE 5 


\section{IZA Discussion Papers}

No Author(s)

141 R. Hujer M. Wellner

142 J. J. Dolado

F. Felgueroso

J. F. Jimeno

143 P. J. Luke

M. E. Schaffer

144 G. Saint-Paul

145 M.-S. Yun

146 T. K. Bauer

J. P. Haisken-DeNew

147 M. Belot

J. C. van Ours

148 L. Goerke

149 R. Lalive

J. C. van Ours

J. Zweimüller

150 J. DiNardo

K. F. Hallock

J.-St. Pischke

151 M. Ward

152 J. J. Dolado

F. Felgueroso

J. F. Jimeno

153 A. S. Kalwij

M. Gregory

154 M. Gerfin

M. Lechner

155 J. Hansen
Titel

Area

Date

The Effects of Public Sector Sponsored Training on Individual Employment Performance in East Germany

Explaining Youth Labor Market Problems in Spain: 3 Crowding-Out, Institutions, or Technology Shifts?

Wage Determination in Russia: An Econometric 4 Investigation

$4 / 00$

Flexibility vs. Rigidity: Does Spain have the worst of 1 both Worlds?

Decomposition Analysis for a Binary Choice Model 7

$4 / 00$

Employer Learning and the Returns to Schooling 5

$4 / 00$

$4 / 00$

Does the Recent Success of Some OECD 3

3

Countries in Lowering their Unemployment Rates

Lie in the Clever Design of their Labour Market

Reforms?

Employment Effects of Labour Taxation in an Efficiency Wage Model with Alternative Budget Constraints and Time Horizons

The Impact of Active Labor Market Programs and Benefit Entitlement Rules on the Duration of Unemployment

Unions and the Labor Market for Managers

Gender, Salary and Promotion in the Academic 5 Profession

$5 / 00$

The Role of the Minimum Wage in the Welfare 3 State: An Appraisal

$5 / 00$

Overtime Hours in Great Britain over the Period 3 1975-1999: A Panel Data Analysis

Microeconometric Evaluation of the Active Labour 6 Market Policy in Switzerland

$5 / 00$

$5 / 00$

The Duration of Immigrants' Unemployment Spells: $\quad 1 / 3$ Evidence from Sweden 


\begin{tabular}{|c|c|c|c|c|}
\hline 156 & $\begin{array}{l}\text { C. Dustmann } \\
\text { F. Fabbri }\end{array}$ & $\begin{array}{l}\text { Language Proficiency and Labour Market Per- } \\
\text { formance of Immigrants in the UK }\end{array}$ & 1 & $5 / 00$ \\
\hline 157 & $\begin{array}{l}\text { P. Apps } \\
\text { R. Rees }\end{array}$ & $\begin{array}{l}\text { Household Production, Full Consumption and } \\
\text { the Costs of Children }\end{array}$ & 7 & $5 / 00$ \\
\hline 158 & $\begin{array}{l}\text { A. Björklund } \\
\text { T. Eriksson } \\
\text { M. Jäntti } \\
\text { O. Raaum } \\
\text { E. Österbacka }\end{array}$ & $\begin{array}{l}\text { Brother Correlations in Earnings in Denmark, } \\
\text { Finland, Norway and Sweden Compared to the } \\
\text { United States }\end{array}$ & 5 & $5 / 00$ \\
\hline 159 & $\begin{array}{l}\text { P.- J. Jost } \\
\text { M. Kräkel }\end{array}$ & Preemptive Behavior in Sequential Tournaments & 5 & $5 / 00$ \\
\hline 160 & M. Lofstrom & $\begin{array}{l}\text { A Comparison of the Human Capital and Signaling } \\
\text { Models: The Case of the Self-Employed and the } \\
\text { Increase in the Schooling Premium in the 1980's }\end{array}$ & 5 & $6 / 00$ \\
\hline 161 & $\begin{array}{l}\text { V. Gimpelson } \\
\text { D. Treisman } \\
\text { G. Monusova }\end{array}$ & $\begin{array}{l}\text { Public Employment and Redistributive Politics: } \\
\text { Evidence from Russia's Regions }\end{array}$ & 4 & $6 / 00$ \\
\hline 162 & $\begin{array}{l}\text { C. Dustmann } \\
\text { M. E. Rochina- } \\
\text { Barrachina }\end{array}$ & $\begin{array}{l}\text { Selection Correction in Panel Data Models: An } \\
\text { Application to Labour Supply and Wages }\end{array}$ & 6 & $6 / 00$ \\
\hline 163 & $\begin{array}{l}\text { R. A. Hart } \\
\text { Y. Ma }\end{array}$ & Why do Firms Pay an Overtime Premium? & 5 & $6 / 00$ \\
\hline 164 & $\begin{array}{l}\text { M. A. Shields } \\
\text { S. Wheatley Price }\end{array}$ & $\begin{array}{l}\text { Racial Harassment, Job Satisfaction and Intentions } \\
\text { to Quit: Evidence from the British Nursing } \\
\text { Profession }\end{array}$ & 5 & $6 / 00$ \\
\hline 165 & P. J. Pedersen & $\begin{array}{l}\text { Immigration in a High Unemployment Economy: } \\
\text { The Recent Danish Experience }\end{array}$ & 1 & $6 / 00$ \\
\hline 166 & $\begin{array}{l}\text { Z. MacDonald } \\
\text { M. A. Shields }\end{array}$ & $\begin{array}{l}\text { The Impact of Alcohol Consumption on Occupa- } \\
\text { tional Attainment in England }\end{array}$ & 5 & $6 / 00$ \\
\hline 167 & $\begin{array}{l}\text { A. Barrett } \\
\text { J. FitzGerald } \\
\text { B. Nolan }\end{array}$ & $\begin{array}{l}\text { Earnings Inequality, Returns to Education and } \\
\text { Immigration into Ireland }\end{array}$ & 5 & $6 / 00$ \\
\hline 168 & $\begin{array}{l}\text { G. S. Epstein } \\
\text { A. L. Hillman }\end{array}$ & $\begin{array}{l}\text { Social Harmony at the Boundaries of the Welfare } \\
\text { State: Immigrants and Social Transfers }\end{array}$ & 3 & $6 / 00$ \\
\hline 169 & R. Winkelmann & $\begin{array}{l}\text { Immigration Policies and their Impact: The Case of } \\
\text { New Zealand and Australia }\end{array}$ & 1 & $7 / 00$ \\
\hline 170 & $\begin{array}{l}\text { T. K. Bauer } \\
\text { K. F. Zimmermann }\end{array}$ & $\begin{array}{l}\text { Immigration Policy in Integrated National } \\
\text { Economies }\end{array}$ & 1 & $7 / 00$ \\
\hline 171 & $\begin{array}{l}\text { C. Dustmann } \\
\text { F. Windmeijer }\end{array}$ & $\begin{array}{l}\text { Wages and the Demand for Health - A Life Cycle } \\
\text { Analysis }\end{array}$ & 5 & $7 / 00$ \\
\hline 172 & D. Card & $\begin{array}{l}\text { Reforming the Financial Incentives of the Welfare } \\
\text { System }\end{array}$ & 3 & $7 / 00$ \\
\hline 173 & D. S. Hamermesh & Timing, Togetherness and Time Windfalls & 5 & $7 / 00$ \\
\hline
\end{tabular}



M. Ward

180 T. K. Bauer I. N. Gang

E. Wasmer

Y. Zenou

184 M. Corak

B. Gustafsson

T. Österberg

185 H. Bonin

K. F. Zimmermann

A. S. Kalwij

A. Zaidi 
223 M. Rosholm

Wages, Training, and Job Turnover in a Searchformer Soviet Union to Israel: Who is coming when?

228 G. Brunello

The College Wage Gap in 10 European

S. Comi Countries: Evidence from Two Cohorts

C. Lucifora

L. Modesto 